\title{
Isolation and identification of Rhizosphere Mycoflora of Lycopersicum Esculentum (tomato)
}

\begin{abstract}
Research was conducted on isolation and identification of Rhizosphere Mycoflora of tomato (Lycopersicum esculentum). Rhizosphere soil samples used for the study were collected from Kwakwalawa village located within Usmanu Danfodiyo University Sokoto. The whole plant (shoot and root) were dug out of the field using hoe, serial dilution of the soil sample were first carried out. Sample inoculation was carried was carried out using potato dextrose agar media. A total number of five fungi were isolated Aspergillus niger, Aspergillus fumigatus, Aspergillus oryzae, Rhizopus oryzae and Rhizopus stolinifer. Aspergillus fumigatus and Aspergillus niger had the highest percentage frequency of occurrences of $33.33 \%$, Rhizopus oryzae and Rhizopus stolinifer had the lowest percentage frequency of occurrence of $6.67 \%$ respectively. Conclusively Inspite of immense amount of work already accomplished in the investigating the micro flora of the soil it must be admitted that no one has yet been able to give a clear picture of all life in the soil and of all interaction of different groups of living things. Developing novel methodologies to study rhizosphere ecology under the natural condition is needed and will required collaboration between plant biologists, ecologists, and soil scientist to develop the rhizotron system where biochemical and molecular biology studies could be performed on site.
\end{abstract}

Volume 8 Issue 6 - 2018

\author{
Shinkafi SA, Gobir MA \\ Department of Microbiology, Usmanu Danfodiyo University \\ Sokoto, Nigeria
}

Correspondence: Shinkafi SA, Department Of Microbiology,
Usmanu Danfodiyo, University Sokotonigeria, Nigeria, Email saadatushinkafi@rocketmail.com

Received: April 16, 2018 | Published: December 20, 2018

\section{Introduction}

Tomato scientifically known as (Lycopersicum esculentum) is an herbaceous plant usually sprawling on ground in the solanceae family. They are close family to tobacco, chilli pepper, and egg plant. Its perennial often grown outdoors in temperate climate as an annual typically reaching to $1-3 \mathrm{~m}$ (3-10feet) in height, weak, woody stem that often vines over other plant Tomatoes are widely used condiment or as food dietary supplement in various part of the world and also valuable in the food industry in their study stated that tomatoes are fourth most commonly consume fresh and vegetable the American diet and showed the connection between the creased tomatoes consumption and reduce risk for both cardiovascular disease and prostate cancer thus make it valuable food source all over the world (Jay et al., 2000). The word tomato come from a word in the nahuatt language tomato the specific name Lycopersicon mean "wolf peach" (compared related species Solanum lycopersicum whose specific name means "wolf fruit" common name "wolf apple" and they are major food of candies in south America tomato product has some nutritional benefit for human health which gives it some unique attribute. Tomato juice is used and could be taken to prevent blood clot. About one cup of tomato to juice per day offer anticlotting benefit (Murray et al., 2012) red tomato has the following nutritional value for $100 \mathrm{~g}$; energy $20 \mathrm{kcal}-80 \mathrm{kj}$ carbohydrate $4 \mathrm{~g}$; sugar $2.6 \mathrm{~g}$ dieter fiber $1 \mathrm{~g}$ fat 0.2 protein $1 \mathrm{~g}$ vitamin $\mathrm{C}(13 \mathrm{mg})-22 \%$ and water 95g (Herson, and Hulland, 1999) other components include lycopene which is a red fat soluble pigment found in vegetable commonly found in tomato which also add to it nutritive value tomato product also offer important nutrient like vitamin $\mathrm{A}$ vitamin $\mathrm{C}$ potassium and fiber (Jeffery et al., 2012). The fungi co-exist with other organism do to the many biotic and a biotic factor in the environment which are favorable to the occupation of common habitat, the term rhizosphere is the defined as the soil volume adjacent to the root and influence by them and represent an area of intense microbial activities in which the organic nutrient is coming from the root favored the development of micro organism these nutrient are originated by decimation of the cell and exudates such sugar organic acid amine compound as well as other substance released by the root (Meting and Dekker, 2002) Thus the rhizosphere of plant that accumulate carbohydrate in the root and as well as the plant material in decomposition are common source of microbiota able to produce useful metabolite for industry inulinase producing microorganism may be selected by plating techniques from the rhizosphere of plant whose root contain inulin like taraxacum officinarum rope (lion tooth) member of the asteraceae this study accessed the fungal diversity at tomato rhizosphere (Nam et al., 2000). Mycorrhiza have been associated with vascular plants since the Paleozoic era, arbuscular mycorrhizae (AM), the most prevalent plant-fungus association; comprise about 150 species, belonging to the order Glomales of Zygomycotina, the arbuscular mycorrhizal (AM) symbiosis is an association between most terrestrial plants and a class of fungi (Glomeromycota) which occurs in the roots of host plants, the fungus receives carbohydrates (sugars) and growth factors from the plant, which in turn receives many benefits, including increased nutrient absorption. They are found in all kinds of soil but more where chemical fertilizers are not used. They have the ability to improve fertility of soil. Colonization of roots by AM fungi has been shown to improve productivity of numerous crop plants in soils under drought stress. ${ }^{1}$ Ultimately AM fungi improve soil structure by binding soil particles together. Tomato (Mill.) belongs to family Solanaceae. It was originated in western South America. Tomato is an herbaceous perennial, but is usually grown as an annual crop in temperate regions.

The fruit is a berry with 2 to 12 locules containing many seeds. Most tomato varieties have red fruits, due to the red carotenoid lycopene. Tomato is highly esteemed as a source of vitamin C, vitamin A and protein. Tomato juice contains 19 amino acids, principally glutamic acid. There are many reports on arbuscular Mycorrhiza, 
microbial communities, nutrient availability, and soil aggregates in organic tomato production. ${ }^{2}$ Phosphorus uptake by a community of arbuscular mycorrhizal fungi was studied by. ${ }^{3}$ Studied the characterization of novel Mycorrhiza-specific phosphate transporters from and uncovering functional redundancy in symbiotic phosphate transport in solanaceous species. Tomato is cultivated in Maharashtra as a chief commercial crop, survey of literature do not show any report on association of AM Fungi with tomato in this area. The study of this association will definitely be useful to all tomato growers to increase yield and to improve fertility of soil. The present work is done with respect to qualitative and Lycopersicon esculentum. ${ }^{4}$ As the Rhizosphere contain lot of organic substances which harbor a high content of microorganism especially fungi. Species richness is usually high in the Rhizosphere and root free soil but distinctly low in the rhizoplane. It has been estimated that one gram of surface soil contain 50,000 to a million fungi, the loss of organic material from root provides the energy for the development of active fungal population in the Rhizosphere around the root. This research will help us to identify which types of fungi associated with Rhizosphere of tomato.

\section{Materials and methods}

\section{Sample Collection}

Rhizosphere soil samples used in the case study were collected from Kwakwalawa village which was located within Usmanu Danfodiyo University Sokoto, in Sokoto North local government Sokoto state. The Rhizosphere soil sample was collected; the plants with root were dug out of the field using a hoe. The Rhizosphere soil samples were transported to the mycology laboratory of Usmanu Danfodiyo University Sokoto in clean polythene bag for further processing and analysis.

\section{Serial Dilution}

The Rhizosphere soil and the root with it adhering soil was carefully cut off and place in to $250 \mathrm{mls}$ conical flask containing $100 \mathrm{ml}$ of sterile distilled water. Similarly $1 \mathrm{~g}$ of Rhizosphere soil sample was introduced into a test tube containing $9 \mathrm{ml}$ of sterile distilled water. Suspension prepared was labeled and vigorously shaken. Serial dilution was prepared by pippeting $1 \mathrm{ml}$ from stock suspension and inoculates in to $9 \mathrm{ml}$ of sterile distilled water in a labeled test tubes and shaking vigorously to obtain $10^{-9}$ dilution $1 \mathrm{ml}$ was further pipette from the first dilution and introduced in to another labeled test tube to obtain $10^{-1}$ dilution. They were repeated done to obtain up to $10^{-9}$ dilution (Rockville et al.,)

Table I Morphological and Cultural Characteristic of the Isolated Fungi

\section{Inoculation and incubation}

$0.1 \mathrm{ml}$ each from $10^{-4}$ and $10^{-5}$ dilutions were inoculated in PDA plates and swabbed to ensure even distribution of inoculums in the medium. Also $0.5 \mathrm{ml}$ each was taken directly from the stock suspension and inoculated into PDA agar plate and swabbed as above. All plate were labeled and incubated at room temperatures for 5 to 6 days. After incubation the fungal colonies will be developed (Gaithersburg, 2000).

\section{Sub culturing and incubation}

Fully developed colonies with different cultural characteristic were subculture using sterile inoculating needles in to freshly prepared PDA plates. Each colony was considered to have originated from one fungal propagules Sub cultured plates were incubated at room temperatures for 3-5 days to obtain pure cultures of the various fungal types. (Mc Donald 1999).

\section{Microscopic identification}

Slides were prepared using the following procedure:

Placing a drop of fungal stain using mounting needle on the clean slide and carefully teased (spread). A drop of lacto phenol cotton blue was added on fungal stain and cover slip was placed on top. Then, examine under microscope using $\mathrm{x} 40$ objectives The fungi were identified by way of microscopic method in conjunction with mycological legend identification of isolates were restricted to genetic level (Havold, 1999).

\section{Results}

The results obtained from the research carried out. Indicated that five (5) fungal isolates were isolated. Table 1 indicated the morphological characteristics of the isolated fungi. The results of the fungi isolated with their frequency of occurrences are presented in Table 2. Aspergillus fumigatus and Aspergillus niger occurred five times each, followed by Aspergillus oryzae which occurred three times, fungi with the least of occurrences were Rhizopus oryzae and Rhizopus stolinifer. Table 3 indicated the percentage frequency of occurrences of the isolated fungi. From the result it was observed that Aspergillus niger and Aspergillus fumigatus had the highest percentage frequency of occurrences of $33.33 \%$ each, followed by Aspergillus oryzae with $20.00 \%$ and then Rhizopus oryzae and Rhizopus stolinifer with $6.67 \%$ each.

\begin{tabular}{|c|c|}
\hline Fungal Isolate & Colony Texture \\
\hline Aspergillus niger & Colonies consisting of a compact white yellowish with dense of dark brown to black. \\
\hline $\begin{array}{l}\text { Aspergillus } \\
\text { fumigatus }\end{array}$ & Colonies consisting of a dense felt of dark green conidiophores intermixed with aerial hyphae \\
\hline Rhizopus stolinifer & Colonies whitish becoming-greenish due to the brownish sporangiosphores and brown black sporangia. \\
\hline Rhizopus oryzae & $\begin{array}{l}\text { Colony whitish becoming-gray with age, about } 10 \mathrm{~mm} \text { high. Stolons smooth or slightly rough almost colorless almost } \\
\text { too yellowish brown. }\end{array}$ \\
\hline Aspergillus oryzae & $\begin{array}{l}\text { Colonies consisting of a felt of long conidiophores often intermixed with aerial mycelium. Pale greenish yellow, later } \\
\text { becoming light to dull brown. }\end{array}$ \\
\hline
\end{tabular}


Table 2 Frequency of Occurrences of the Isolated Fungi

\begin{tabular}{ll}
\hline Fungal Isolate & Number of Occurrences \\
\hline Aspergillus niger & 5 \\
Aspergillus fumigatus & 5 \\
Aspergillus oryzae & 3 \\
Rhizopus oryzae & 1 \\
Rhizopus stolinifer & 1 \\
TOTAL & 15 \\
\hline
\end{tabular}

Table 3 Percentage Frequency of Occurrences of the Isolated Fungi

\begin{tabular}{ll}
\hline Fungal Isolate & Percentage of occurrences (\%) \\
\hline Aspergillus fumigatus & $33.33 \%$ \\
Aspergillus niger & $33.33 \%$ \\
Aspergillus oryzae & $20.00 \%$ \\
Rhizopus oryzae & $6.67 \%$ \\
Rhizopus stolinifer & $6.67 \%$ \\
Total Percentage & $100 \%$ \\
\hline
\end{tabular}

\section{Discussion}

The result obtained in this research indicated that Aspergillus fumigatus and Aspergillus niger has the higher percentages and high number of occurrences. The highest number of fungal species isolated from the rhizosphere is not surprising, due to the production of substrate by growing root in the form of root exudates containing amino, sugar, organic acid, nucleotide and other substrate. Thus, this lead to their proximity to the roots and subsequent proliferation and multiplication of the mycoflora in the soil region. Also high rate of microbial decomposition of both organic and sloughed off tissue (plant) is yet another factor of their abundance compared with the field soil where such activities are minimal. The fungal flora acts as universal agent of decay, from which new life continually arises and is nourished, the fungi makes a unique contribution to the maintenance of soil fertility. Apart from the saprophytic fungi which act as scavengers, a number of important plant parasitic fungi live in the soil and attack economically, important plants through their roots or at the ground level (Smith, 2000). The obligate saprophytic fungi isolated were genera of Aspergillus which affect the tomatoes only when they are kept during storage period. Also they add to the total biomass of fungi in the soil and advantageous in the decomposition of organic matter which enhances soil fertility. It was also noted that, the intense microbial activity in the soil (i.e. from both harmful and beneficial microbes) can be especially important because it may result in suppression or even elimination of photogenic microorganism. Among the parasitic fungi isolated in this research a member of the generus Rhizopus was isolated and this may cause certain disease when condition are favorable ${ }^{5-20}$ Wielding and Emerson (2003) show their importance in the field, by stating that some specific strain of Rhizopus e.g. Rhizopus oryzae is used in the production of alcoholic beverage in part of Asia and Africa and it also lives on the world wide in the organic matter it also found to affect carrots, pineapples, and mangoes and also Rhizopus stolinifer are found to causes fruit rot on strawberry, tomato and sweet potato and used in commercial production of fumaric and cortisone (Zheng et al., 2007).

\section{Conclusion}

The result of this study indicated that five fungal isolate where isolated which include the Aspergillus niger, Aspergillus fumigatus, Aspergillus oryzae, Rhizopus oryzae and Rhizopus stolinifer, which indicate that out of these fungal isolate Aspergillus niger and Aspergillus fumigatus has the higher percentage frequency of occurrence of $33.33 \%$, followed by Aspergillus oryzae which has $20.00 \%$, while the Rhizopus oryzae and Rhizopus stolinifer has the least percentage frequency of occurrence of $6.67 \%$ respectively. Inspite of immense amount of work already accomplished in the investigating of microflora of soil it must be admitted that no one has yet been able to give a clear picture of all life in the soil and of all interaction of different group of living thing. However, an understanding of these interaction is incomplete due to the difficulty of studying underground process under controlled yet realistic condition.

\section{Acknowledgments}

None.

\section{Conflicts of interest}

The authors declared there is no conflict of interest.

\section{References}

1. Al-Karaki GN. Benefit, cost and water-use efficiency of arbuscular mycorrhizal durum wheat grown under drought stress. Mycorrhizae. 2001;8(1):41-45.

2. Cavagnaro TR, Jackson LE, Ferris JH, et al. Arbuscular mycorrhizae, microbial communities, nutrient availability, and soil aggregates in organic tomato production. Plant and Soil. 2006;282(1-2):209-225.

3. Solaiman MZ, Abbott LK. Phosphorus uptake by a community of arbuscular mycorrhizal fungi in jarrah forest. Plant and Animals. 2003; 19(1-2): 313-320.

4. Azcón R, Ruiz-Lozano JM, Rodriguez R. Differential contribution of arbuscular controlled experiment in the scientific method with For promoting crop productivity in Improved Trichoderma spp. Trends in Biotechnology. 2001;7:34-38.

5. Myrold DD. Mycorrhizal fungi to plant nitrate uptake under increasing $N$ supply to the soil. Canadian Microorganisms: DE Alexander, RW Fairbridge, et al. editors. Kluwer Academic Publishers, the Netherlands; 2000 .

6. Agrios GN. Plant Pathology. 5th Ed. Elsevier Academic Press: 2005;54-365 p.

7. Al-Karaki, GN, Al-Raddad A. Effects of arbuscular mycorrhizal fungi and drought stress on growth and nutrient uptake of two wheat genotypes differing in drought resistance. Mycorrhiza. 2001;7(2):83-88.

8. Annuum LCV. San Luis with arbuscular Mycorrhiza indigenous to Mexico. Scientia Azcón R, E Ambrosano, C Charest et al. editors. Nutrient acquisition in mycorrhizal lettuce. Horticulture 2003;92:347-359.

9. Boutton TW. Alleviation of drought stress of Chile ancho pepper. (Capsicum Taylor, T.N. (1999). Fungal Associations in Terrestrial Pale Ecosystems. 2002;5:21-25.

10. Davies FT, V Olalde-Portugal, L Aguilera-Gomez, et al. Zinc uptake by corn as affected by vesicular-arbuscular mycorrhizae. Plant Soil. 2000;129(2):121-130. 
11. Gabor, Brad, Wiebe, et al. Tomato diseases a practical guide for seeds men. Journal of Botany.1997;79: 1175-1180.

12. Gari B, Giani VA. Impact of microbial diversity in soil micro organism in soil role in genesis and function. Soil biology. 2005;19-15.

13. Gaur A, MP Snarma, Adholeya A. Production quality vegetables through Microbial health of rhizosphere retrieved in 5, may 2006. Mycorrhiza, microbial communities, nutrient availability, and soil aggregates in organic Mycorrhizae. Indian Horticulture, 2003;48:19-21.

14. George E, H Marschner, I, Jackson. Role of arbuscular mycorrhizal fungi in uptake of growers, and advisors. Growth, root architecture and $\mathrm{P}$ acquisition. Mycorrhiza. 1999;14:185-192.

15. Morton JB, SP Bentivenga. Levels of diversity in endomycorrhizal fungi (Glomales, Zygomycetes) and theirrolein defining taxonomic and non taxonomic groups. Journal of Plant and Soil. 1999;282:209-225.
16. Perry DA, Amaranthus MP, Borchers JG. et al. Special emphasis on biological control. Bootstrapping in Ecosystems. 2000;39:230-237.

17. Schenk NC. Plants under different phosphorous and nitrogen concentration. Plant Science 165: Can mycorrhizae control root diseases. 2001;65:230-234.

18. Schussler A, Schwartzzott D, Walker C. Anew phylum, the Glomeromycota: phylogeny and evolution. Mycological Research. 2001;105(12):1413-1421.

19. Simon L. Phylogeny of the Glomales: Deciphering the past to understand the present. Physiopathology. 2002;74:1019-1021.

20. Sylvia DM, Hammond LC, Bennett JM, et al. Field response of maize to a VAM fungus and water management. Agronomy Journal. 1999;85(2):193-198. 